\title{
DA INATIVIDADE AO SENTIMENTO DE UTILIDADE DA PESSOA IDOSA: EFEITO NA REDUÇÃO DOS SINTOMAS DE ANSIEDADE E DEPRESSÃO
}

\author{
Rosa Cândida Carvalho Pereira de Melo \\ Unidade de Investigação em Ciências da Saúde: Enfermagem (UICISA:E) \\ Escola Superior de Enfermagem de Coimbra \\ rosamelo@esenfc.pt \\ Andreia Sofia Pereira de Melo \\ Mestre em Evolução e Biologia Humanas pela Faculdade de Ciências e Tecnologia da Universidade de Coimbra \\ andreiaspmelo@gmail.com
}

Recepción Artículo: 13 mayo 2021 Admisión Evaluación: 13 mayo 2021 Informe Evaluador 1: 19 mayo 2021

Informe Evaluador 2: 28 mayo 2021

Aprobación Publicación: 02 junio 2021

\begin{abstract}
RESUMO
A inatividade e a falta de reconhecimento social têm consequências negativas, podendo levar a comportamentos de agitação, depressão e complicações causadas pela imobilidade. Neste contexto, torna-se fundamental ocupar a pessoa idosa para que se sinta útil. Este estudo pretende avaliar o efeito da mudança de contexto familiar e do cuidado em Humanitude no sentimento de utilidade da pessoa idosa. Foi realizado um estudo de caso, de cariz exploratório e descritivo, longitudinal (realizado ao longo de 4 anos), numa pessoa idosa (94 aos 98 anos), em contexto domiciliar, antes da mudança do contexto familiar, 2 e 4 anos após esta mudança. Nestes três momentos foram avaliados os seguintes parâmetros: depressão pela Escala de Depressão Geriátrica de Yesavage - versão curta; nível de dependência das Atividades Instrumentais de Vida Diária (AIVD) pela escala de Lawton e Brody; sinais vitais; fármacos consumidos; e comportamentos de agitação psicomotora. Verificou-se efeito positivo da mudança do contexto familiar e da utilização dos procedimentos cuidativos Humanitude na pessoa idosa em estudo, nomeadamente: redução dos sintomas de depressão, de depressão grave (14), para sem depressão (5); melhoria dos níveis de dependência nas AIVD, de dependência total (1), para dependência moderada (5); diminuição dos valores da tensão arterial (TA), de 170/90mmhg, para 100/75mmhg; redução dos fármacos prescritos e consumidos, de 12 fármacos diários para 1 fármaco; observou-se uma redução na frequência e intensidade dos comportamentos de agitação psicomotora (tremores, irritabilidade e labilidade emocional). Verificouse ainda aumento da satisfação na participação nas AIVD. Foi evidenciado que a forma como interagimos com a pessoa idosa pode ter efeitos na sua saúde e no seu comportamento. Assim, a formação dos cuidadores formais
\end{abstract}




\section{DA INATIVIDADE AO SENTIMENTO DE UTILIDADE DA PESSOA IDOSA: EFEITO NA REDUÇÃO DOS SINTOMAS DE ANSIEDADE E DEPRESSÃO}

e informais é importante para darem intencionalidade na valorização da participação ativa da pessoa idosa em atividades com que se identifique e que the restitua o sentimento de utilidade social.

Palavras-chave: idoso; família; cuidadores informais; utilidade social

\section{ABSTRACT}

From inactivity to the feeling of utility of the elderly person: effect on reducing symptoms of anxiety and depression. Inactivity and lack of social recognition have negative consequences, which can lead to agitation, depression and complications caused by immobility. In this context, it is essential to occupy the elderly person to make them feel useful. This study intends to evaluate the effect of the change in family context and care in Humanitude on the feeling of usefulness of the elderly person. An exploratory and descriptive, longitudinal case study (carried out over 4 years) with an elderly person (94 to 98 years old), in household context, before the family context changed, 2 and 4 years after this change. In these three moments, the following parameters were evaluated: depression by the Yesavage Geriatric Depression Scale - short form; level of dependence on Instrumental Activities of Daily Living (IADL) Scale by Lawton and Brody; vital signs; drugs consumed; and psychomotor agitation behaviors. There was a positive effect of changing the family context and using Humanitude care procedures in the elderly person under study, namely: reduction of depression symptoms, from severe depression (14), to no depression (5); improvement of IADLs dependency levels, from total dependence (1), to moderate dependence (5); decrease in blood pressure (TA) values, from 170/90mmhg, to 100/75mmhg; reduction of drugs prescribed and consumed, from 12 drugs daily to 1 drug; there was a reduction in the frequency and intensity of psychomotor agitation behaviors (tremors, irritability and emotional lability). There was also an increase in satisfaction with participation in IADLs. It was shown that the way we interact with the elderly person can have effects on their health and behavior. Thus, the training of formal and informal caregivers is important to give intentionality to the valorization of the active participation of the elderly person in activities with which they identify and which restores the feeling of social utility.

Keywords: elderly; family; informal caregivers; social utility

\section{INTRODUÇÃO}

0 envelhecimento demográfico é uma realidade a nível mundial, registando-se em 2019, 703 milhões de pessoas com mais de 65 anos (United Nations, 2019). Portugal insere-se neste contexto caracterizando-se hoje por ser uma sociedade bastante envelhecida, em que $21,7 \%$ da população possui mais de 65 anos (Pordata, 2019c). Para este indicador tem contribuído o aumento da esperança média de vida à nascença (Pordata, 2019a), a qual se deve aos avanços da medicina preventiva e curativa, contribuindo para a melhoria da saúde pública. Também o investimento na educação, a promoção da saúde e a melhoria nas condições sociais, são fatores explicativos do aumento da esperança média de vida. Segundo os dados mais recentes, em Portugal, estima-se que quem completar 65 anos, possa viver em média mais 20,4 anos, sendo superior à média europeia, de 19,9 anos (Pordata, 2019b).

Associado ao envelhecimento aumentam as comorbilidades, levando à dependência física e cognitiva incapacitante, e à inatividade com impacto a nível do cérebro, do sistema endócrino (hormonal) e na musculatura esquelética. Assim, a manutenção de atividades de vida diárias é capaz de preservar a mobilidade e a capacidade funcional do idoso, garantindo a sua autonomia, independência e sentimento de utilidade tão importante para a qualidade de vida das pessoas idosas.

Torna-se, pois fundamental que se considerem as particularidades dos idosos, a sua história de vida, os seus desejos, e que de preferência se mantenham no domicílio, dado que os idosos que residem na comunidade reportam níveis mais elevados de suporte social comparativamente aos participantes em estrutura residencial para idosos (Luz \& Miguel, 2015).

A manutenção da pessoa idosa no domicílio e em contexto de uma família funcional permite a satisfação das necessidades do idoso ao nível físico e emocional (Almeida et al., 2012). Assim, este contexto de cuidado pode 
representar conforto, segurança, identidade e preservação das lembranças de toda uma vida, sendo considerado o local preferido para viver, não obstante as divergências e conflitos familiares que por vezes podem ocorrer (Sousa et al., 2006). No entanto, apesar de a família ser o "local ideal para viver todas as etapas do nosso desenvolvimento" (Gomes \& Mata, 2012, p. 163), a forma como a família lida com a situação de dependência e as alterações cognitivas, acaba por impor a exclusão social, uma vez que está focada na fragilidade e na incapacidade, não sendo preservada a sua Humanitude.

Humanitude é um conceito antropológico definido por Albert Jacquard (1987) como sendo as dádivas que os homens oferecem uns aos outros desde que têm consciência de o ser e que continuam a oferecer-se num enriquecimento sem limites. Segundo Salgueiro (2014, p. 17) "os olhares, palavras, toques, sorrisos, estímulos à verticalidade que recebemos dos nossos ancestrais, de geração em geração, fizeram de nós o que hoje somos. Construíram a nossa Humanitude". Tendo por base o conceito antropológico de Humanitude, Yves Gineste e Rosette Marescotti desenvolveram a Metodologia de Cuidado Humanitude (MCH). Esta metodologia de cuidado é sustentada pela filosofia de Humanitude, norteada por princípios éticos, nomeadamente: prestar cuidados com zero cuidados de força, respeitar a singularidade e individualidade, viver e morrer de pé, abrir a estrutura residencial ao exterior e transformar estas residências em lugares de vida e onde se respeitam as vontades (Simões et al., 2012). Salgueiro (2014) adverte para a importância de respeitarmos a dignidade do ser humano e para manifestarmos esse respeito em cada olhar, palavra, toque e sorriso, transmitindo-Ihe o sentimento de ser reconhecido e permitindo-Ihe reconhecer-se como ser humano. A MCH, através de uma abordagem relacional estruturada, tendo por base os princípios de Humanitude e as regras de arte, permite sistematizar e operacionalizar a relação entre 0 cuidador e a pessoa cuidada, com enfoque nas suas forças de vida e potenciais existentes nas pessoas e seus cuidadores informais (familiares) (Melo \& Melo, 2020). Estes cuidados são prestados de forma consciente tendo por base os princípios de atuação que promovem a autonomia, o bem-estar e a dignidade, conforme 0 legalmente estabelecido na portaria 38/2013 que regulamenta o Serviço de Apoio Domiciliário (Ministério da Solidariedade e da Segurança Social, 2013).

A implementação desta metodologia de cuidado tem evidenciado resultados positivos nos cuidadores e nas pessoas dependentes e/ou com quadros demenciais associados. Nos cuidadores tem-se verificado uma maior facilidade no estabelecimento da relação com a pessoa cuidada, melhor compreensão dos comportamentos, contribuindo assim para uma maior aceitação dos cuidados, redução dos níveis de ansiedade e, redução do consumo de psicotrópicos, assim como a promoção do autocuidado (Figueiredo et al., 2018; Melo et al., 2019).

\section{OBJETIVO}

Este estudo pretende avaliar o efeito da mudança de contexto familiar e do cuidado em Humanitude, na redução de sintomas de depressão e no aumento do sentimento de utilidade da pessoa idosa.

\section{METODOLOGIA}

Foi realizado um estudo de caso, de cariz exploratório e descritivo, Iongitudinal (realizado ao longo de 4 anos), numa pessoa idosa (94 aos 98 anos), em contexto domiciliar, antes da mudança do contexto familiar, 2 e 4 anos após esta mudança. Nestes três momentos foram avaliados os seguintes parâmetros: depressão pela Escala de Depressão Geriátrica de Yesavage - versão curta (Sheikh \& Yesavage, 1986); nível de dependência das Atividades Instrumentais de Vida Diária (AIVD) pela escala de Lawton e Brody, validada por Araújo et al. (2007) numa amostra de idosos não institucionalizados; sinais vitais; fármacos consumidos; e comportamentos de agitação psicomotora.

\section{ANÁLISE E DISCUSSÃO DOS ACHADOS}

Este estudo de caso descreve o percurso de uma pessoa idosa dos 94 aos 98 anos de idade. Esta cresceu e morou numa aldeia do interior de Portugal durante 90 anos, trabalhou na agricultura durante toda a sua vida, desde criança, não tendo tido oportunidade de frequentar a escola. 
Ao longo do seu percurso existencial teve muitos fracassos, desilusões e frustrações. Foi vítima de agressões, maus-tratos de várias ordens, infidelidade e abandono dos seus familiares mais próximos. Sofreu várias perdas, a morte de um filho recém-nascido e do marido com doença oncológica. Tinha dois filhos vivos, mas estava de relações cortadas há vários anos com um deles.

Devido a algumas comorbilidades, que the estavam a provocar dependência nos autocuidados, nos últimos 4 anos passou a morar com a sua filha, genro e neta em meio urbano. Esta filha era, para si, a pessoa mais significativa e com quem tinha ligação afetiva mais próxima. Apesar disso, segundo a própria referia, nunca se sentiu aceite e compreendida neste agregado familiar. Relatava que diariamente era sujeita a palavras negativas proferidas com grande violência: "Se eu abria a boca, gritavam logo 'cale-se, vá para o quarto'!", "Sentia uma negrura muito grande!". Passava grande parte do tempo no quarto, isolada, segregada da sociedade e com pouco contacto social, sentindo-se inútil e sem reconhecimento.

No mês de maio de 2014 a sua filha, com doença oncológica em fase terminal, estava em grande sofrimento, preocupada com a sua mãe idosa dependente, com comportamentos de agitação e agressividade provocadores de conflitos familiares. Esta idosa e a sua família estavam a necessitar de ajuda, pois apresentavam muita dificuldade na gestão das emoções. Pelo que a idosa mudou de agregado familiar, indo morar com uma família de acoIhimento.

Tendo vivido em ambiente familiar disfuncional, apresentava comportamentos de agitação psicomotora (tremores, irritabilidade e labilidade emocional); sintomas de depressão grave (14); dependência total nas AIVD (1); Hipertensão arterial (170/90 mmhg); obstipação crónica, ansiedade, alterações do padrão do sono, síndrome vertiginoso provocando-Ihe desequilíbrio e dificuldade motora, necessitando de auxiliares de marcha. Polimedicada (12 medicamentos): Diazepam $5 \mathrm{mg}$ (ao deitar); Pregabalina $75 \mathrm{mg}$ (2x dia); Tramadol + Paracetamol (2x dia); Nifedipina $20 \mathrm{mg}$ (2x por dia); Enalapril + Hidroclorotiazida $20 \mathrm{mg}$ (1x dia); Dinitrato de isossorbida $20 \mathrm{mg}$ (1x dia); Beta-histina 16 mg (2x dia); Dicloridrato de trimetazidina, 35 mg (2x dia); Ácido acetilsalicílico 100 mg (1x dia); Paracetamol $1000 \mathrm{mg}$ (2x ao dia); Furoato de mometasona e Lactulose líquida $10 \mathrm{~g} / 15 \mathrm{ml}$ (1x dia).

Na família de acolhimento um membro tinha formação em MCH e todos tinham experiência em cuidar de pessoas idosas uma vez que nesse momento cuidavam de uma avó com 100 anos de idade. A família de acolhimento aceitou cuidar desta pessoa idosa respeitando as suas particularidades, os seus hábitos, vontades e desejos.

\section{Redução dos sintomas de depressão}

Durante os 4 anos verificou-se redução dos sintomas de depressão, de depressão grave (14) avaliada no primeiro ano, para sem depressão (5) no $2^{0}$ e $4^{0}$ ano de mudança de agregado familiar. Devido ao seu passado de sofrimento, abandono e maus tratos referia frequentemente: "Sinto uma negrura muito grande! Não tenho ninguém no mundo! Durante toda a minha vida fui sempre muito "desinfeliz'!", "0 que é que ando a fazer neste mundo? Eu quero que Deus me leve". 0 percurso doloroso da sua vida era bem patente no seu comportamento, na tristeza profunda, na labilidade emocional, nas suas defesas, ressentimentos, medo, insegurança e desconfiança. Segundo Salgueiro (2014) é preciso uma observação atenta para compreender estas marcas na autoestima, autoconceito e autoimagem. Muitas vezes são consequência de olhares, palavras e gestos duros, arrogantes, frios, intimidantes e desconsiderantes que não validam a Humanitude do idoso. Para esta autora quando a Humanitude é maltratada por estímulos agressivos ou pela indiferença, as vítimas sofrem danos irreparáveis, deixando de se considerar pessoas humanas, desistem de viver, seguindo-se rapidamente a morte física. Os idosos necessitam de ser reconhecidos como pessoas humanas, respeitando a sua dignidade, dado que segundo Peplau (1997) reconhecer e ser reconhecido permite fortalecer a personalidade e a emancipação.

Como estava em conflito com 0 filho, com 0 qual não se comunicava há vários anos, 0 que lhe provocava grande angústia e sofrimento por se sentir abandonada e desprezada, foi feito um esforço para o restabelecimento da relação entre os dois. A idosa referia muitas vezes "Olhe que é muito triste não ter ninguém no mundo! Ser 
desprezada pelo próprio filho é muito triste!". Foi-Ihe também dada a liberdade de contactar e socializar com as pessoas significativas, nomeadamente os familiares que residiam nos Estados Unidos da América, com os quais já não contactava há vários anos. Este contacto era realizado pelo telefone ou por videochamada. Ela ficava muito contente e grata dizendo: "Eu nunca pensei que ia ser tão bem tratada no fim da minha vida! Deus é tão amigo dos pobres!". Honneth (2006) refere que na relação afetiva de reconhecimento da família o ser humano é reconhecido como um ser carente recebendo encorajamento afetivo reciproco e estima social que Ihes permita a valorização das suas capacidades. Para este autor quando não há reciprocidade de reconhecimento, a interação é unilateralizada, não se tendo em consideração a individualidade de cada ser humano. Esta situação pode gerar desconfiança, influenciando a possibilidade de autorrealização, fazendo com que a pessoa se sinta desrespeitada, abandonada, menosprezada e com sentimento de inutilidade (Fuhrmann, 2013).

\section{Sentimento de utilidade social}

Para aumentar o sentimento de utilidade, como toda a sua vida trabalhou na agricultura, foi-lhe dada a oportunidade de cuidar do jardim. Gostava muito de 'augar' (regar) como ela dizia muitas vezes: "Tenho que ir augar, as plantinhas precisam de muita água senão morrem! Vocês não percebem nada da 'ingricultura' eu é que sei!". Sentia-se muito feliz quando ensinava como se cultivavam as plantas e se dava atenção ao que dizia. Sendo dado o reforço positivo e valorização ao conhecimento que transmitia.

Outra atividade que gostava muito de fazer era estender, apanhar e dobrar a roupa. Nos dias de sol ficava muito agitada e impaciente, queria sempre roupa para estender, referindo com frequência: "Não tem roupa para lavar? É uma pena, está um sol tão lindo! Faça lá um grande favor, vá lá pôr a roupa a lavar!". Enquanto a máquina de lavar a roupa lavava, no andar inferior, ela subia e descia as escadas várias vezes para verificar se a máquina já tinha terminado. Quando esta parava, mas o programa de lavagem ainda não tinha terminado, ia logo anunciar que a roupa já estava pronta para a irem buscar. Por vezes era difícil fazê-la compreender o porquê de a máquina estar parada e a roupa ainda não estar lavada. Nos dias em que não havia roupa para lavar era problemático, a idosa ficava muito agitada e ansiosa porque gostava de estar ocupada e de se sentir útil. Estender a roupa era uma atividade em que ela podia demonstrar a sua utilidade, passando o dia inteiro ocupada a estender e a dobrar roupa. Nestes dias não se queixava com dores nem aparentava estar deprimida, sentia-se feliz e realizada, afinal era uma atividade que gostava de fazer e que desenvolveu ao longo de toda a vida. Não deixava que ninguém mexesse na roupa, ficava muito agitada e respondia de uma forma muito ríspida: "Fuja daqui! Eu é que trato da roupa! Eu é que sei estender a roupa! Vocês não percebem nada disto! Acha que eu não sou competente para estender a roupa?". Nestes momentos de agitação e ansiedade era necessário falar com ela de forma calma e tranquila, olhando-a de frente e ao mesmo nível, abraçando-a, agradecendo o trabalho que fazia, demonstrando que era útil e muito competente e que gostávamos dela. Depois acalmava-se e pedia desculpa dizendo "Sou a pessoa mais 'desinfeliz' do mundo! Porque é que eu sou assim? Desculpem vocês não têm culpa nenhuma". Estes comportamentos de defesa nas interações sociais, agitando-se com facilidade, eram devidas à história de vida conturbada que vivenciou, sendo necessário dar intencionalidade à forma e conteúdo da comunicação verbal e não verbal, nomeadamente através do olhar partilhado, de frente, horizontal, progressivamente próximo, frequente e terno, demonstrando ternura e igualdade; comunicação verbal, através da utilização de palavras positivas e tranquilizantes, de reconhecimento e elogio valorizando as suas capacidades; e o toque suave e amplo (ex: abraço) (Melo \& Melo, 2020). A intencionalidade dada na utilização destes pilares relacionais permitiu que ao longo do tempo ficasse mais calma e tranquila e aumentasse a sua segurança e autoconfiança.

\section{Normalização dos sinais vitais e redução da toma da medicação}

Dado ser hipertensa e tomar medicação anti-hipertensora, foram sendo avaliados e registados os sinais vitais, nomeadamente a pressão arterial e a frequência cardíaca, tendo-se verificado redução dos valores da pressão arterial de 170/90 mmhg, no início da mudança do contexto familiar, para 100/75 mmhg, no $2^{0}$ ano e 90/50 mmhg no $4^{\circ}$ ano. Dada a redução dos valores da pressão arterial, em articulação com a médica de família, foi rea- 


\section{DA INATIVIDADE AO SENTIMENTO DE UTILIDADE DA PESSOA IDOSA: EFEITO NA REDUÇÃO DOS SINTOMAS DE ANSIEDADE E DEPRESSÃO}

lizada a conciliação medicamentosa, sendo suspensos os medicamentos anti hipertensores. Como foi manifestando menos queixas relacionadas com as dores músculo-esqueléticas, menor agitação, ansiedade e insónias foram sendo redúzios os medicamentos ansiolíticos e analgésicos. Assim, dos 12 medicamentos iniciais: Diazepam $5 \mathrm{mg}$ (ao deitar); Pregabalina $75 \mathrm{mg}$ (2x dia); Tramadol + Paracetamol (2x dia); Nifedipina $20 \mathrm{mg}$ (2x por dia); Enalapril + Hidroclorotiazida $20 \mathrm{mg}$ (1x dia); Dinitrato de isossorbida $20 \mathrm{mg}$ (1x dia); Beta-histina 16 mg (2x dia); Dicloridrato de trimetazidina, 35 mg (2x dia); Ácido acetilsalićlico 100 mg (1x dia); Paracetamol $1000 \mathrm{mg}$ (2x ao dia); Furoato de mometasona e Lactulose líquida $10 \mathrm{~g} / 15 \mathrm{ml}$ (1x dia), passou a tomar um medicamento (Ácido acetilsalicílico $100 \mathrm{mg}, 1 \times \mathrm{dia}$ ).

\section{Redução dos níveis de dependência}

Ao longo dos quatro anos de mudança do contexto familiar verificou-se melhoria dos níveis de dependência nas Atividades Instrumentais de Vida Diária (AIVD), de dependência total (1) no início, para dependência moderada (5) no $2^{\circ}$ e $4^{0}$ ano em análise. Tendo-se verificado aumento na participação nas atividades instrumentais de vida diária, como utilização do telefone, lavar pratos, fazer a cama, tratar a roupa (estender, apanhar e dobrar), participar na preparação das refeições e tomar a medicação.

Neste período foi promovida a sua autonomia e independência no autocuidado de higiene, tendo-se começado por conhecer os seus hábitos e desejos, estimulando-a e incentivando-a a lavar-se e auxiliando apenas no que não conseguia fazer sozinha, nomeadamente ajudar a entrar e sair da banheira, lavar as costas e os pés. Este autocuidado era realizado quando a idosa queria, normalmente à noite antes de se deitar, e da forma como desejava. Como gostava da água bem quente e com o jato forte nas costas, provocava-Ihe sensações agradáveis, referindo: "Que consolo a água está tão quentinha! Que Deus a console no céu como me consola a mim!". No final do banho chorava de alegria, dizendo: "Que sorte tão grande, eu não merecia... Fico tão consolada! Também no estudo de Henriques et al. (2021) é referido que o estímulo e incentivo para que a pessoa inicie os gestos cuidativos e a valorização de todos os progressos conseguidos aumentou a independência e autonomia, promovendo 0 desenvolvimento das suas potencialidades. Como nunca foi valorizada durante a sua vida havia a preocupação por parte da família de acolhimento de a elogiar em tudo o que ia conseguindo fazer, nomeadamente no seu autocuidado de higiene, no vestir e despir, a idosa ficava muito satisfeita querendo fazer cada vez mais e melhor. 0 que está de acordo com o referido por Gineste e Pellissier (2008) sobre a importância de se valorizar a pessoa e os esforços realizados no cuidado. Esta forma de cuidar permite respeitar a autonomia e a dignidade da pessoa, garantindo as condições existenciais para o bem-estar, além de propiciar e promover a sua participação ativa e corresponsável no seu quotidiano (António, 2017; Melo et al., 2017).

\section{Redução dos comportamentos de agitação psicomotora}

Com a mudança para um ambiente, mais calmo e tranquilo, a promoção do respeito pela sua autonomia, independência e valorização enquanto pessoa, foi-se verificando redução dos comportamentos de agitação psicomotora, manifestando menos períodos de ansiedade e agitação. No entanto, queixava-se muitas vezes das cuidadoras do apoio domiciliário, que vinham ajudar na alimentação, dizendo: "Não consigo ouvir nada do que dizem porque falam muito alto, parece que estão a gritar". Por vezes recusava alimentar-se, tendo uma das cuidadoras verbalizado: "Olhe que saí daqui com uma angústia muito grande, só me apetecia chorar, porque acho que não fui profissional! Ela estava tão agitada. Eu dava-Ihe o comer e os medicamentos e ela cuspia fora, mordeu-me! Foi muito difícil tive que fazer as coisas à força! Fiquei angustiada por não saber o que fazer!". Neste caso a idosa manifestou comportamentos de defesa, interpretados pelas cuidadoras como agressividade, por incompreensão do cuidado, pela forma como é realizado e devido ao meio ambiente muito ruidoso (Mlinac \& Feng, 2016). Foi-Ihe explicado que quando houvesse recusa em comer não deveriam obrigar, deveriam abordála de frente, colocar-se ao mesmo nível, falar de forma calma (sem falar muito alto e com tom agudo, pois provoca agitação) e negociar sobre 0 que quer comer e quando, visto que normalmente esta estratégia dava resultado. À medida que fomos capacitando as cuidadoras para a forma de realizarem a abordagem para evitar agitação e a 
importância da negociação para reduzir a oposição ao cuidado foi-se verificando melhorias na interação, na redução da agitação e recusa dos cuidados assim como diminuiç̧ão da ansiedade das cuidadoras. Também no estudo de Henriques et al. (2020) foi evidenciado que os cuidadores apresentavam dificuldades na prestação dos cuidados a idosos que se agitavam e que recusavam os cuidados provocando-Ihes ansiedade. Neste estudo, verificouse que a apropriação da Metodologia de Cuidado Humanitude, nomeadamente a sistematização da forma como realizar a abordagem, através da intencionalidade no olhar partilhado, a forma e conteúdo verbal, assim como a forma de tocar, refletiu-se na redução da agitação da pessoa cuidada e na ansiedade dos cuidadores.

\section{CONCLUSÃO}

Neste estudo de caso, foi evidenciado que a forma como interagimos com a pessoa idosa, através de gestos e palavras menos adequadas, pode ter efeitos nefastos na sua saúde e no seu comportamento, provocando a destruição da sua Humanitude. Permitiu também uma reflexão acerca da importância da promoção do sentimento da utilidade social na pessoa idosa, devendo-se respeitar a sua história de vida, os seus hábitos, ritmos, gostos e interesses e outras particularidades, próprias de uma pessoa humana.

Por outro lado, as divergências e conflitos familiares, a forma como a família lida com a situação de dependência e as alterações cognitivas, leva à despersonalização e a comportamentos defensivos, interpretados como agressividade, acabando por impor a inatividade e exclusão social.

A falta de capacitação das famílias para lidarem com as comorbilidades associadas ao envelhecimento, como as alterações dos comportamentos, nomeadamente agitação e recusa de cuidado leva ao aumento do consumo de medicação psicotrópica e aumento da dependência pela perda de competências sociais, levando muitas vezes ao sentimento de inutilidade, à estigmatização e descriminação, não sendo preservada a sua Humanitude.

Torna-se, portanto, necessário a capacitação dos cuidadores formais e informais, onde se incluem as famílias, com competências relacionais, para saberem atuar nestas situações, contribuindo para promoverem a autonomia e da independência da pessoa idosa, estimulando-as a participar ativamente nas atividades de vida diárias, permitindo a manutenção no contexto domiciliar, evitando a institucionalização e a exclusão social.

Assim, consideramos que devem ser desenvolvidos mais estudos utilizando amostras representativas de forma a corrigir as limitações da investigação atual e compreender melhor como cuidar a pessoa idosa preservando 0 seu sentimento de utilidade social e consequentemente a sua dignidade.

\section{REFERÊNCIAS BIBLIOGRÁFICAS}

Almeida, L., Azevedo, R. C. de S., Reiners, A. A. 0., \& Sudré, M. R. S. (2012). Cuidado realizado pelo cuidador familiar ao idoso dependente, em domicílio, no contexto da estratégia de Saúde da Família. Texto \& Contexto - Enfermagem, 21(3), 543-548. https://doi.org/10.1590/S0104-07072012000300008

António, M. A. (2017). Humanitude: do conceito antropológico a uma ferramenta de cuidar. In Unidade de Investigação em Ciências da Saúde: Enfermagem (UICISA: E) Escola Superior de Enfermagem de Coimbra (ESEnfC) (Ed.), Higiene e conforto: da tarefa ao cuidar com Humanitude (pp. 83-94).

Araújo, F., Pais Ribeiro, J., A., 0., Pinto, C., \& Martins, T. (2007). Validação da escala de Lawton e Brody numa amostra de idosos não institucionalizados. In I. Leal, J. Pais-Ribeiro, I. Silva, \& S. Marques (Eds.), Actas do 70 congresso nacional de psicologia da saúde (pp. 217-220). ISPA.

Figueiredo, A., Melo, R., \& Ribeiro, 0. (2018). Humanitude care methodology: difficulties and benefits from its implementation in clinical practice. Revista de Enfermagem Referência, IV Série(17), 53-62. https://doi.org/10.12707/RIV17063

Fuhrmann, N. L. (2013). Luta por reconhecimento: reflexões sobre a teoria de Axel Honneth e as origens dos conflitos sociais. Barbarói, 38, 79-96.

Gineste, Y., \& Pellissier, J. (2008). Humanitude, cuidar e compreender a velhice (Instituto). Instituto Piaget, Piaget Editora. 
Gomes, M. J., \& Mata, A. (2012). A família provedora de cuidados ao idoso dependente. In F. Pereira (Ed.), Teoria e prática da gerontologia: um guia para cuidadores de idosos (1st ed., pp. 163-174). Psico \& Soma Livraria, Editora, Formação e Empresas, Lda.

Henriques, L. V. L., Melo, R. C. C. P. de, \& Martins, A. (2021). Metodologia de cuidado Humanitude: contributo para a dignificação da pessoa nos cuidados de higiene. 11(2), 8-15.

Henriques, L. V. L., Melo, R. C. C. P. de, Pereira, M. P. L. de 0., Henriques, A., Martins, M. A. N., \& Alves, R. E. D. G. (2020). Desafios no cuidar dos idosos: contributo da metodologia de cuidado Humanitude na redução da ansiedade dos cuidadores. In Ciências Humanas: Afeto, Poder e Interações 2 (pp. 236-247). Atena Editora. https://doi.org/10.22533/at.ed.54220081021

Honneth, A. (2006). 0 Capitalismo Como Forma De Vida Fracassada: Esboço Sobre a Teoria Da Sociedade De Adorno. Revista De Ciências Sociais - Política \& Trabalho, 24(0), 9-26.

Jacquard, A. (1987). Cinq milliards d'hommes dans un vaisseau. Seuil.

Luz, M. H. R. A. da, \& Miguel, I. (2015). Apoio social e solidão: Reflexos na população idosa em contexto institucional e comunitário. Revista Portuguesa de Investigação Comportamental e Social, 1(2), 3-14. https://doi.org/10.7342/ismt.rpics.2015.1.2.20

Melo, R., Araújo, J. P., Abreu, C. da C., Oliveira, A. S., Fernandes, A. M., \& Sá, M. da C. A. de. (2017). Cuidados de higiene e conforto: contributo da metodologia de cuidado humanitude para a dignificação da pessoa cuidada Rosa. In Unidade de Investigação em Ciências da Saúde: Enfermagem (UICISA: E) Escola Superior de Enfermagem de Coimbra (ESEnfC) (Ed.), Higiene e conforto: da tarefa ao cuidar com Humanitude (pp. 107124).

Melo, R., Costa, P. J., Henriques, L. V. L., Tanaka, L. H., Queirós, P. J. P., \& Araújo, J. P. (2019). Humanitude in the humanization of elderly care: experience reports in a health service. Revista Brasileira de Enfermagem, 72(3), 825-829. https://doi.org/10.1590/0034-7167-2017-0363

Melo, R., \& Melo, A. (2020). Humanitude no resgate da dignidade da pessoa idosa: estudo de caso. In R Pocinho et al. (Ed.), 0 envelhecimento como um todo, livro de atas do Ageingcongress 2020. Thomson Reuters Arazadi.

Ministério da Solidariedade e da Segurança Social. (2013). Portaria n. ${ }^{0}$ 38/2013.

Mlinac, M. E., \& Feng, M. C. (2016). Assessment of Activities of Daily Living, Self-Care, and Independence. Archives of Clinical Neuropsychology, 31(6), 506-516. https://doi.org/10.1093/arclin/acw049

Peplau, H. E. (1997). Peplau's Theory of Interpersonal Relations. Nursing Science Quarterly, 10(4), 162-167. https://doi.org/10.1177/089431849701000407

Pordata. (2019a). Esperança de vida à nascença: total e por sexo (base: triénio a partir de 2001).

Pordata. (2019b). Esperança de vida aos 65 anos: por sexo.

Pordata. (2019c). População Residente: Total e por Grandes Grupos Etários.

Salgueiro, N. (2014). Humanitude: Um imperativo do nosso tempo: Introdução à metodologia de cuidado Gineste-Marescotti (I. Portugal-Humanitude. (ed.); IGM Portug). IGM Portugal-Humanitude.

Sheikh, J. I., \& Yesavage, J. A. (1986). Geriatric Depression Scale (GDS): Recent evidence and development of a shorter version. Clinical Gerontologist: The Journal of Aging and Mental Health, 5(1-2), 165-173. https://doi.org/10.1300/J018v05n01_09

Simões, M., Salgueiro, N., \& Rodrigues, M. (2012). Cuidar em Humanitude: estudo aplicado em cuidados continuados. Revista de Enfermagem Referência, III Série(6), 81-93. https://doi.org/10.12707/RIII1177

Sousa, L., Figueiredo, D., \& Cerqueira, M. (2006). Envelhecer em família: os cuidados familiares na velhice. Ambar.

United Nations. (2019). World Population Ageing 2019 - Highlights. 